\title{
Effect of cure cycle on curing process and hardness for epoxy resin
}

\author{
J. Zhang, Y. C. Xu, P. Huang* \\ State Key Laboratory of Materials-Oriented Chemical Engineering, College of Chemistry and Chemical engineering, \\ Nanjing University of Technology, Nanjing - 210009, China
}

Received 10 April 2009; accepted in revised form 4 June 2009

\begin{abstract}
A 3-dimensional finite element model is developed to simulate and analyze the temperature and degree of cure field of epoxy casting part during cure process. The present model based on general finite element software ABAQUS is verified by literature example and experimental data. The numerical results show good agreement with literature example and measured data, and are even more accurate than the simulation of literature. After modeling successfully, the influence of temperature cure cycle ramps have on the temperature and degree of cure gradient is investigated. Moreover, the effect of non-uniform temperature and degree of cure field within epoxy casting part on hardness is demonstrated. The present model provides an accurate and novel method that allows further insight into the process of cure for epoxy resin.
\end{abstract}

Keywords: thermosetting resins, epoxy resin, temperature field, degree of cure field, hardness

\section{Introduction}

From their discovery by Pierre Castan in 1938 to nowadays, epoxy resins kept on attracting the interests of the industry and academia community. This is because they maintain an excellent balance between various properties such as adhesion properties, electrical insulation properties, humidity resistance, heat resistance, and mechanical properties [1-5].

Determination of cure cycle is one of the important factors for successful fabrication of thick epoxy product with dependable quality and at low cost. The first concern is a non-linear increase in internal temperature induced by the exothermic chemical reaction of epoxy, resulting in temperature overshoot. The second concern relates to the complex temperature and degree of cure gradients that develop during the curing process. Non-uniform curing can lead to incomplete cure or resin degradation and entrapped volatiles or voids, which may ultimately cause a reduction in the overall quality and in service performance of the finished component. Therefore, numerical simulation was attempted to predict temperature rise during cure and the cure simulation was applied to suggest an optimal cure cycle for specific epoxy structures. Although few works focused on the cure simulation of epoxy, there have been many numerical models on the curing of thick thermosetting matrix composites, which can be applied to epoxy either.

Loos and Springer [6] developed a one-dimensional model to simulate the curing process of a flat-plate by solving the governing equation using finite difference method. Lee and coworkers [7-9] studied modeling for cure simulation of thick composite cylinders. They established one-dimensional cure model using the finite difference method. Bogetti and Gillespie [10] also used finite difference method to develop a two-dimensional cure simulation analysis of thick thermosetting compos- 
ites. They compared their simulation result with measured data and predicted the temperature and degree of cure distributions within an arbitrary cross-sectional geometry. White and Hahn $[11,12]$ proposed an optimal temperature cycle that can reduce residual stress during cure of composite structures. Ciriscioli et al. [13] developed an algorithm that can minimize void and residual stress inside the composite structure. They measured the temperature, ionic conductivity and compaction in thick graphite/epoxy laminates, and the data were compared to the results calculated by the LoosSpringer CURE model. Twardowski et al. [14] compared the experimental temperature profiles of a thick part to the results calculated by a onedimensional simulation, from which the effect of initial degree of cure was investigated. Hojjati and Hoa [15] established model based on dimensionless parameters for cure of thermosetting composites and predicted the temperature and degree of cure fields of a thick composite. White and Kim [16] proposed the stage cure technique for fabricating thick composites and investigated the effect of stage cure on the mode I interlaminar fracture toughness and shear strength. Yi et al. [17] conducted the finite element simulation by assuming thermal properties as a function of temperature and degree of cure. Kim and Lee [18] developed an autoclave cure cycle with cooling and reheating steps for thick thermosetting composite laminates using finite difference analysis. They indicated that the developed cure cycle was effective for reducing temperature overshoot. Blest et al. [19] developed a model including resin flow, heat transfer, and the cure of multiplayer thermosetting composite laminates during an autoclave processing, which was validated by comparing the numerical results with the experimental data. Park and Lee [20] developed a two-dimensional cure simulation by finite element method. They calculated through-the-thickness temperature distributions of arbitrary shape composite structures including the mandrel. Oh and Lee [21] studied the cure cycle for glass/epoxy composite laminate by 3 -dimensional finite element model based on commercial finite element software ANSYS. An optimized cure cycle with the cooling and reheating steps was developed by minimizing the objective function to reduce the temperature overshoot in the composite. Park et al. [22] introduced a three-dimensional finite element model that can be used for cure simulation of composite structures with arbitrary geometry under non-uniform autoclave temperature distribution. Guo et al. [23] developed a cure model for thermosetting matrix laminates also based on ANSYS, and proved the conventional cure cycles recommended by prepreg manufacturers for thin laminates should be modified to reduce out-of-plane temperature gradient. Yan [24] developed a twodimensional finite element model to simulate and analyze the mechanisms pertaining to resin flow, heat transfer, and consolidation of laminates during autoclave processing. Numerical examples, including a comparison of the numerical results with onedimensional and two-dimensional analytical solutions, were given to validate the finite element formulation. Yan [25] conducted two-dimensional cure simulation of thick thermosetting composites by using a weighted residual method. Numerical examples proved that heat transfer anisotropy has an important effect on the temperature field.

In most of the previous researches, the temperature and degree of cure fields were simulated using one or two dimensional finite difference analysis. Only a few literatures studied the temperature and degree of cure fields by finite element analysis. Although several special-purpose numerical softwares have been developed to study the curing process, few analyses made by general-purpose numerical software $[21,23]$ were published. Because general-purpose finite element software has well developed pre- and post-processors, researchers can be released from the tedious programming work, and devote their most efforts to the explanation and employment of the simulation results. In the previous studies [5, 21, 23], general finite element software ANSYS were used for predicting curing of resin matrix composites and also for casting resins. But large amount of code was still needed, and programmed by APDL (ANSYS parametric design language). Compared with ANSYS, finite element analytic software ABAQUS has original advantage in dealing with non-linear coupled problems. ABAQUS subroutines in FORTRAN provide a convenient and flexible way for defining degree of cure, cure kinetic equation, and heat outflow process. Moreover, the decoupling of heat conduction equation and cure kinetics equation can be accomplished by ABAQUS automatically. The objective of this study is to gain a fundamental 
understanding of the cure process unique to thick epoxy casting product. Three-dimensional transient heat transfer finite element model during cure cycle for a thick epoxy cylinder part is established by ABAQUS with its subroutines. The simulation of the cure process accounts for thermal and chemical interactions during cure process. The effect of temperature cycle on the hardness of epoxy is also discussed.

\section{Heat conduction analysis and FEM equations}

The heat conduction process of resin materials curing is a transient thermal transfer process with nonlinear internal heat generation source, which is from the exothermic enthalpy of resin curing process. According to Fourier's heat conduction equation and energy conservation law, the mathematical model was established as Equation (1):

$$
\begin{aligned}
& \rho_{r} V_{r} H_{r} \frac{\mathrm{d} \alpha}{\mathrm{d} t}+k_{x x} \frac{\partial^{2} T}{\partial x^{2}}+k_{y y} \frac{\partial^{2} T}{\partial y^{2}}+k_{z z} \frac{\partial^{2} T}{\partial z^{2}}= \\
& =\rho C_{p} \frac{\partial T}{\partial t}
\end{aligned}
$$

where $k_{x x}, k_{y y}, k_{z z}$ are heat transfer coefficients of $x$, $y$ and $z$ directions, respectively; $\rho$ and $C_{p}$ are the density and the specific heat of composite material; $\rho_{r}, V_{r}, \alpha, \mathrm{d} \alpha / \mathrm{d} t$ are the density, volume fraction, degree of cure, curing rate of resin; $H_{r}$ is the exothermic enthalpy from resin curing process. The rate of cure could be expressed by the function of degree of cure and time, the formula of which is given through the study of resin curing kinetics (Equation (2)):

$$
\frac{\mathrm{d} \alpha}{\mathrm{d} t}=f(\alpha, t)
$$

The FEM equations of Equation (1) are well documented and the reader is referred to the text by the Park [20] in this regard. Newton-Raphson iteration with quadratic convergence is employed to solve nonlinear problems in this paper. Using 3-D 8 nodes element DC3D8 in ABAQUS, the degree of freedom of nodes are temperature and degree of cure. The heat outflow process of resin is defined by ABAQUS subroutine HETVAL; degree of cure is defined by ABAQUS subroutine USDFLD; the convection boundary condition is defined by ABAQUS subroutine FILM; temperature boundary condition is defined by ABAQUS subroutine DISP.

\section{Experimental}

\subsection{Materials and sample preparation}

The resin used in this paper was obtained by mixing diglycidyl ether of bisphenol-A(DGEBA)-based epoxy (E-51 and E-20 from Wuxi resin factory, the epoxy equivalent of which is 196 and 500 respectively) and cure agent DAMI (long chain flexible aromatic amine, amine equivalent is 517 , developed by advanced polymer materials institute, Nanjing University of Technology). The mass ratio of E-51/E-20/DAMI is 1:1:0.922. The mixture was prepared at $130^{\circ} \mathrm{C}$ with continuous stirring for 2 minutes, and then poured into the cylindrical glass-mould of $12 \mathrm{~cm}$ diameter.

\subsection{Temperature and mechanical property measurements}

The cylindrical glass-mould with the resin sample was put in an oven heated by air with preset temperature profile. The temperature profiles at various locations within the epoxy casting part were measured by thermocouple, and recorded by computer. The hardness values of samples were tested by Shore D-type hardness instrument.

\section{Results and discussion}

\subsection{Literature example model verification}

Employing the data from literature [10] for validation, [0/90] glass/polyester laminate is studied and the material property is listed in Table 1 . The composite curing kinetic equation was given as Equation (3):

$\frac{\mathrm{d} \alpha}{\mathrm{d} t}=A \exp \left(-\frac{\Delta E}{R T}\right) \alpha^{m}(1-\alpha)^{n}$

The values of parameters of above equation are listed in Table 2, where $A$ is pre-exponential coefficient, $\Delta E$ is activation energy, $R$ is universal gas

Table 1. Thermal properties of glass/polyester composite

\begin{tabular}{|c|c|c|c|}
\hline $\begin{array}{c}\rho \\
{\left[\mathbf{k g} \cdot \mathbf{m}^{-3}\right]}\end{array}$ & $\begin{array}{c}\boldsymbol{C}_{\boldsymbol{p}} \\
{\left[\mathbf{J} \cdot \mathbf{k g}^{-\mathbf{1}} \cdot \mathbf{K}^{-\mathbf{1}}\right]}\end{array}$ & $\begin{array}{c}\boldsymbol{k}_{\boldsymbol{x} x} \\
{\left[\mathbf{W} \cdot \mathbf{m}^{-\mathbf{1}} \cdot \mathbf{K}^{-\mathbf{1}}\right]}\end{array}$ & $\begin{array}{c}\boldsymbol{k}_{y y}=\boldsymbol{k}_{z z} \\
{\left[\mathbf{W} \cdot \mathbf{m}^{-\mathbf{1}} \cdot \mathbf{K}^{-\mathbf{1}}\right]}\end{array}$ \\
\hline 1890 & 1260 & 0.4326 & 0.2163 \\
\hline
\end{tabular}


Table 2. Cure kinetics parameters for glass/polyester composite

\begin{tabular}{|l|c|}
\hline$A\left[\mathrm{~min}^{-1}\right]$ & $3.7 \cdot 10^{22}$ \\
\hline$\Delta E\left[\mathrm{~J} \cdot \mathrm{mol}^{-1}\right]$ & $1.674 \cdot 10^{5}$ \\
\hline$m$ & 0.524 \\
\hline$n$ & 1.476 \\
\hline$R\left[\mathrm{~kJ} \cdot \mathrm{kg}^{-1} \cdot \mathrm{mol}^{-1} \cdot \mathrm{K}^{-1}\right]$ & 8.31434 \\
\hline$H_{r}\left[\mathrm{~J} \cdot \mathrm{kg}^{-1}\right]$ & 77500 \\
\hline
\end{tabular}

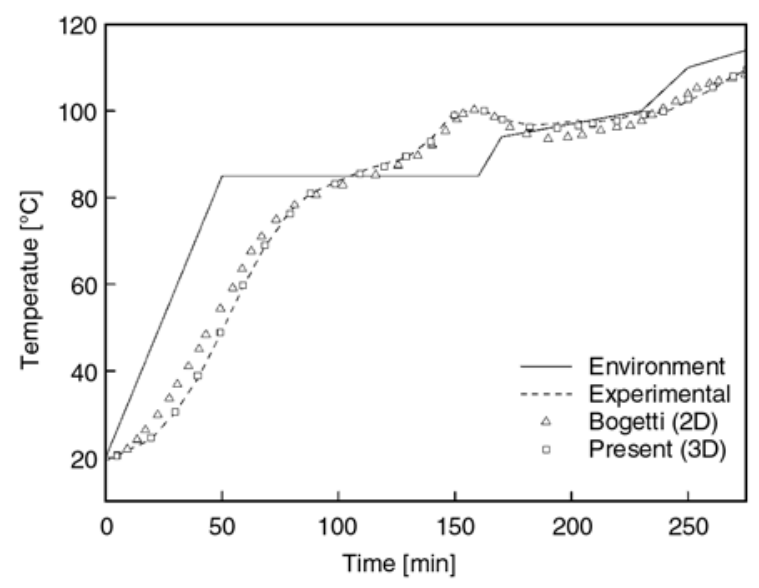

Figure 1. Temperature profiles at the center point of $2.54 \mathrm{~cm}$ thickness laminate

constant, $T$ is absolute temperature, $m$ and $n$ are exponents, and $H_{r}$ is the total heat of reaction.

The dimension of the composite laminate in the example is $15.24 \times 15.24 \times 2.54 \mathrm{~cm}$. The heat convection coefficients $h$ on the top and bottom surfaces are 37.636 and $54.075 \mathrm{~W} \cdot \mathrm{m}^{-2} \cdot \mathrm{K}^{-1}$, respectively. In addition, insulated boundary conditions were employed on the sides to isolate through the thickness effects. Figure 1 gives the comparison of temperature between calculation results and experimental results from the literature, located in the center of the laminate, from which the validation of the model in this paper is verified. It can be also concluded from Figure 1 that the results from the model in this paper is closer to experimental data than the calculation results from the literature [10].

\subsection{Experimental example model verification}

The established model for laminate composite is applied to epoxy resin, after that was verified by literature example. The cure kinetic model of the epoxy resin system described in paragraph 3.1 was obtained conducting isothermal scanning tests by Netzsch DSC204 F1. The reaction rate expression for the epoxy resin was given as Equation (4). Figure 2 shows comparison between the heat flow rate

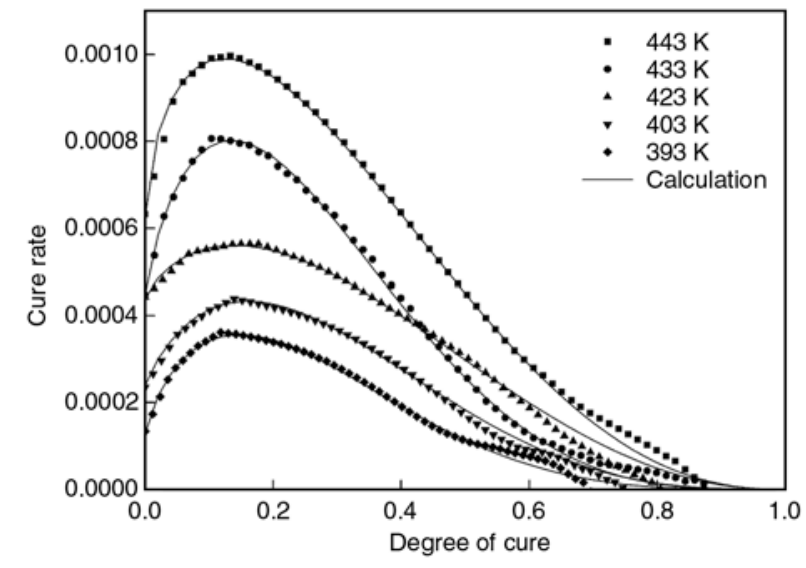

Figure 2. Cure rate versus degree of cure for epoxy

Table 3. Thermal properties of epoxy

\begin{tabular}{|c|c|c|}
\hline $\begin{array}{c}\rho \\
{\left[\mathbf{k g} \cdot \mathbf{m}^{-3}\right]}\end{array}$ & $\begin{array}{c}\boldsymbol{C}_{\boldsymbol{p}} \\
{\left[\mathbf{J} \cdot \mathbf{k g}^{-\mathbf{1}} \cdot \mathbf{K}^{-\mathbf{1}}\right]}\end{array}$ & $\begin{array}{c}\boldsymbol{k}_{x x}=\boldsymbol{k}_{y y}=\boldsymbol{k}_{z z} \\
{\left[\mathbf{W} \cdot \mathbf{m}^{-\mathbf{1}} \cdot \mathbf{K}^{-\mathbf{1}}\right]}\end{array}$ \\
\hline 1225 & 967 & 0.191 \\
\hline
\end{tabular}

Table 4. Cure kinetics parameters for epoxy

\begin{tabular}{|l|c|}
\hline$A_{1}\left[\mathrm{~min}^{-1}\right]$ & 1246.2 \\
\hline$A_{2}\left[\mathrm{~min}^{-1}\right]$ & 49.26 \\
\hline$E_{1}\left[\mathrm{~J} \cdot \mathrm{mol}^{-1}\right]$ & 38330 \\
\hline$E_{2}\left[\mathrm{~J} \cdot \mathrm{mol}^{-1}\right]$ & 20000 \\
\hline$m$ & 0.786 \\
\hline$n$ & 3.207 \\
\hline$R\left[\mathrm{~kJ} \cdot \mathrm{kg}^{-1} \cdot \mathrm{mol}^{-1} \cdot \mathrm{K}^{-1}\right]$ & 8.31434 \\
\hline$H_{r}\left[\mathrm{~J} \cdot \mathrm{kg}^{-1}\right]$ & 277000 \\
\hline
\end{tabular}

measured during the isothermal scanning and those calculated by the cure kinetic model of Equation (4). The developed cure kinetic model agreed well with the experimental results. The thermal properties and cure kinetic parameters of the epoxy resin are presented in Table 3 and Table 4 respectively (Equation (4)).

$\frac{\mathrm{d} \alpha}{\mathrm{d} t}=\left(k_{1}+k_{2} \alpha^{m}\right)(1-\alpha)^{n}$

where $m$ and $n$ are exponents, $k_{1}$ and $k_{2}$ and defined by the Arrhenius rate expressions (Equation (5)):

$$
\begin{aligned}
& k_{1}=A_{1} \exp \left(-\frac{\Delta E_{1}}{R T}\right) \\
& k_{2}=A_{2} \exp \left(-\frac{\Delta E_{2}}{R T}\right)
\end{aligned}
$$

where $A_{1}$ and $A_{2}$ are pre-exponential coefficients, $R$ is universal gas constant, $\Delta E_{1}$ and $\Delta E_{2}$ are activation energies, $T$ is absolute temperature. Because the glass mould is very thin, it was assumed that the 


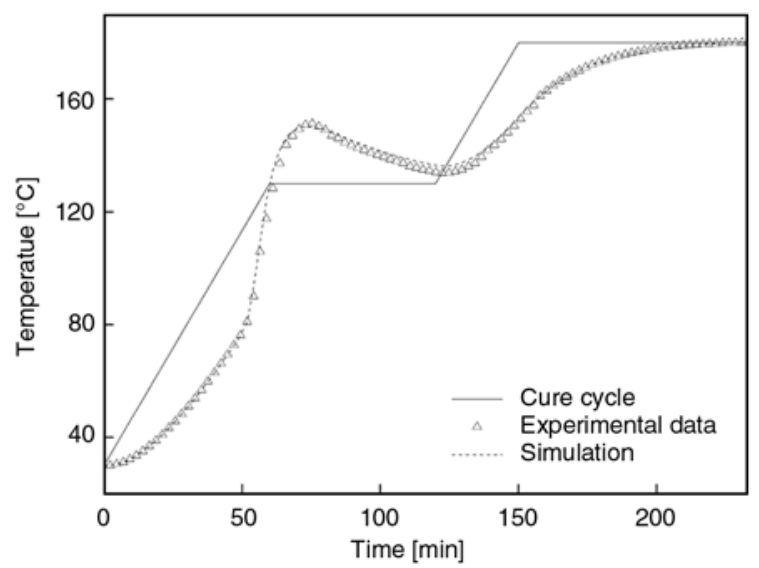

Figure 3. Temperature profile of epoxy cylinder part

resin part contacted with exterior environment directly. The epoxy cylinder part with $12 \mathrm{~cm}$ diameter and $1.2 \mathrm{~cm}$ height was subjected to cure cycle temperature history indicated in Figure 3 with specified $h=5 \mathrm{~W} \cdot \mathrm{m}^{-2} \cdot \mathrm{K}^{-1}$. Figure 3 illustrates the comparison of temperature between calculation results and experimental results of the epoxy concerned, located in the center of the cylinder part, from which the validation of the model is verified.

\subsection{Cure cycle temperature ramp effects}

The cure cycle temperature ramp can strongly influence the temperature and degree of cure gradients that develop during the cure. The effect of the temperature cure cycle ramp on the degree of cure gradients is examined in an epoxy part described above exposed to various cure cycle temperature ramps. The epoxy part with specified temperature and convective boundary conditions $(h=$ $5 \mathrm{~W} \cdot \mathrm{m}^{-2} \cdot \mathrm{K}^{-1}$ ) on all the surfaces is used here respectively. The temperature cure cycle is illustrated in Figure 4. Predicted values of the degree of cure at the center point (point A in Figure 7) minus the degree of cure at the surface point (point $F$ in Figure 7) of the part $\left(\alpha_{c}-\alpha_{s}\right)$ with temperature and convective boundary conditions, are plotted in Figure 5 and Figure 6 as a function of cycle time for the various temperature ramps investigated, respectively.

Both Figure 5 and Figure 6 show a negative peak and the absolute peak value in Figure 6 exceeded in Figure 5. This could be due to that heat transfer by diffusion is low, the surface cure reaction took place earlier than center point, and the heat transfer with temperature boundary condition is more rapid

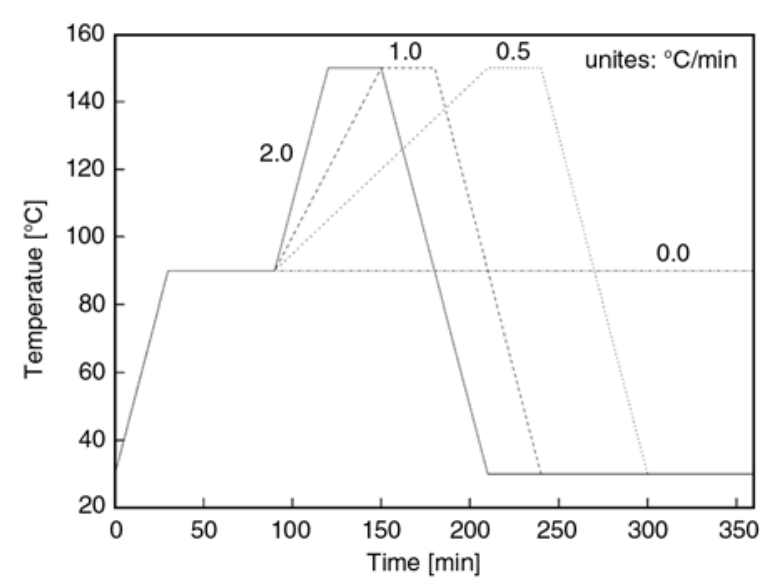

Figure 4. Temperature cure cycle ramps

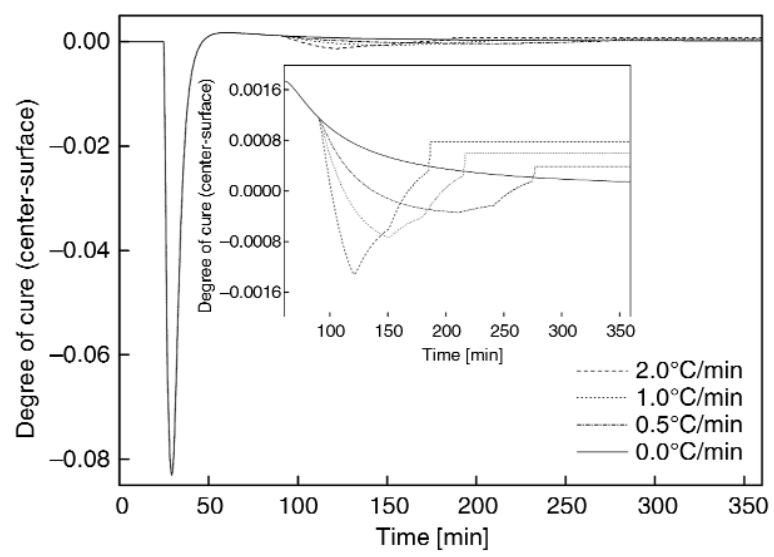

Figure 5. Effect of the temperature ramp on non-uniform curing in epoxy part with temperature boundary condition

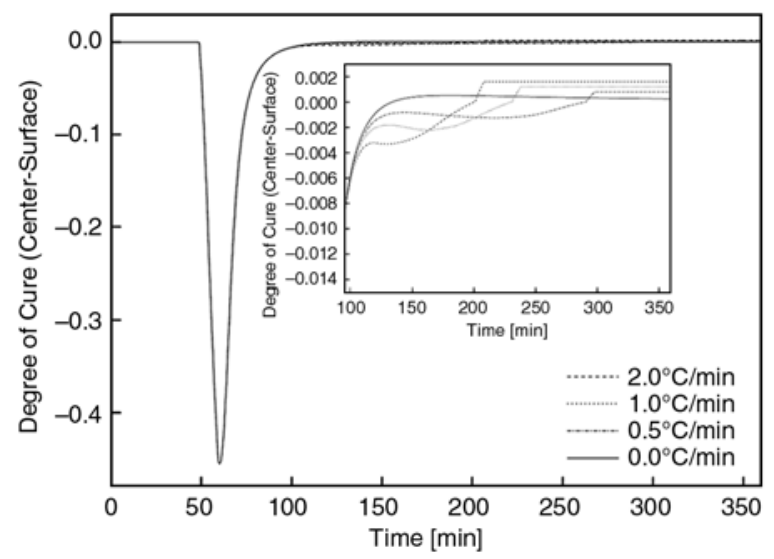

Figure 6. Effect of the temperature ramp on non-uniform curing in epoxy part with convective boundary condition

than with convective boundary condition. It is also concluded that with the temperature ramp increasing, the final value of $\left(\alpha_{c}-\alpha_{s}\right)$ rise. Figure 5 and Figure 6 were locally amplified when the curves deviated from each other. It indicated that the value of $\left(\alpha_{c}-\alpha_{s}\right)$ steadily increased from negative value to 
positive value for convective boundary condition. While for the temperature boundary condition, the value of $\left(\alpha_{c}-\alpha_{s}\right)$ decreased from positive value to negative value, and then increased to positive value again. Otherwise, with the temperature ramp increasing, the absolute negative peak value rise. Consequently, the surface temperature initiates the cure reaction. The exothermic reaction accelerates the cure and as a result creates non-uniform degree of cure field interior the part. Non-uniform curing potentially entraps voids and volatile byproducts of the cure reaction and enhances warpage and residual stress development. It can be concluded that, the temperature ramp can significantly influence the mechanical properties of epoxy plate.

\subsection{Effects on hardness}

Normal mechanical testing can not be conducted in single point of epoxy part, while hardness can reflect tensile strength and Young modulus. Therefore, Shore hardness is used here to evaluate the mechanical property of single point of epoxy part. The tested positions are showed in Figure 7, and the hardness of which (average value of 5 times test) is listed in Table 5. Samples for measurement are the epoxy casting part described above cured at the temperature cycle illustrated in Figure 8, with convective boundary conditions $\left(h=5 \mathrm{~W} \cdot \mathrm{m}^{-2} \cdot \mathrm{K}^{-1}\right)$ on all the surfaces. It was assumed that epoxy resin with higher degree of cure could have higher hardness, but the data listed in Table 5 does not obey this simple rule. Consequently, the mechanical property is not only related to the degree of cure but to the thermal history during cure process. Figure 8 illustrates the thermal history for each point. With-

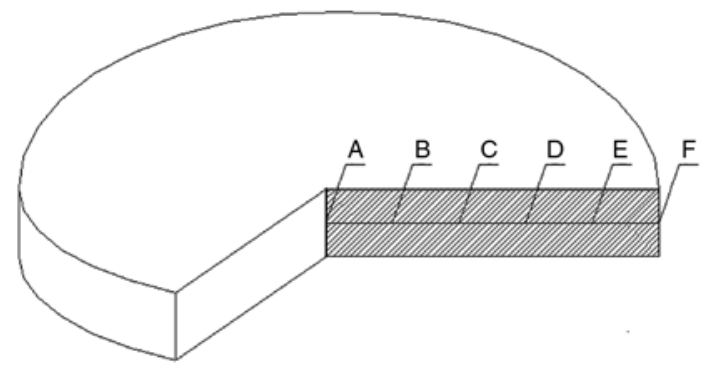

Figure 7. Hardness measurement points of epoxy part

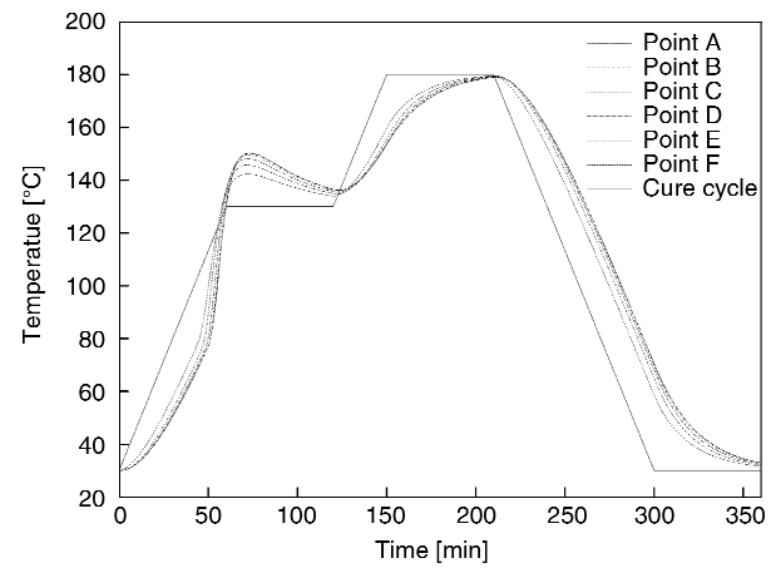

Figure 8. Temperature profiles of epoxy part

out considering the postcure process, the value of temperature peak decreased for point $\mathrm{A}$ to point $\mathrm{F}$, while point $\mathrm{D}$ has the highest Shore hardness. Released heat resulting from exothermic curing reaction is slow to dissipate by conduction inside epoxy part and may potentially raise local temperature to levels risking material degradation or carbonization, which leads to the decline of hardness. On the other hand, because of the non-uniform temperature field interior epoxy part there is relatively low local temperature inside the epoxy part. When local temperature is excessive low, epoxy resin can not cure completely. Low crosslink density decreases the hardness either. It is essential for epoxy resin casting part that designs a proper temperature cycle neither causes temperature overshoot nor resulting in incomplete cure.

\section{Conclusions}

In this paper, a 3-dimensional finite element model based on general finite element software ABAQUS was developed to study the temperature and degree of cure distribution in epoxy casting part during cure process. The present model is validated by example from literature and experimental data. The predicted results show good agreement with literature example and measured data, and are even more accurate than the simulation of literature. By applying present model, the influence of temperature cure cycle ramps have on the temperature and

Table 5. Final degree of cure and hardness of epoxy part

\begin{tabular}{|l|c|c|c|c|c|c|}
\hline \multicolumn{1}{|c|}{ Position } & Point A & Point B & Point C & Point D & Point E & Point F \\
\hline Final degree of cure $\left[10^{-3}\right]$ & 926.115 & 926.104 & 926.091 & 926.040 & 925.874 & 925.346 \\
\hline Shore hardness & 76 & 76 & 82 & 90 & 80 & 74 \\
\hline
\end{tabular}


degree of cure gradient is investigated. Moreover, the effect of non-uniform temperature and degree of cure field within epoxy casting part on hardness is demonstrated. The non-linear internal heat source and heat transfer process causes non-uniform temperature and degree of cure field internal epoxy part. By comparing the calculated temperature profile and degree of cure with Shore hardness of a series of internal locations, it indicates that hardness depends not only on the degree of cure but also on the thermal history during cure process. This work, therefore, represents an accurate and novel method that allows further insight into the process of cure for epoxy resin, which can improve mechanical property and in-service performance of the finished component by reducing warpage and residual stress during the cure process.

\section{References}

[1] Perrin F-X., Nguyen T. M. H., Vernet J-L.: Kinetic analysis of isothermal and nonisothermal epoxyamine cures by model-free isoconversional methods. Macromolecular Chemistry and Physics, 208, 718729 (2007). DOI: $10.1002 / \mathrm{macp} .200600614$

[2] Duan J. K., Kim C. N., Jiang P. K.: On-line monitoring of cycloaliphatic epoxy/acrylate interpenetrating polymer networks formation and characterization of their mechanical properties. Journal of Polymer Research, 16, 45-54 (2009). DOI: $10.1007 / \mathrm{s} 10965-008-9201-7$

[3] Jordan J. L., Foley J. R., Siviour C. R.: Mechanical properties of Epon 826/DEA epoxy. Mechanics of Time-Dependent Materials, 12, 249-272 (2008). DOI: $10.1007 / \mathrm{s} 11043-008-9061-\mathrm{X}$

[4] Jones I. K., Zhou Y. X., Jeelani S., Mabry J. M.: Effect of polyhedral-oligomeric-sil-sesquioxanes on thermal and mechanical behavior of SC-15 epoxy. Express Polymer Letters, 2, 494-501 (2008). DOI: $10.3144 /$ expresspolymlett.2008.59

[5] Kaindl A., Rockelein R., Grindling J., Gehrig M.: Simulation of the curing process upon epoxy-resin casting ofelectrical apparaturses-a flexible way to do this. in 'Electrical Insulating Materials, Proceedings of 1998 International Symposium on 27-30 Sept' 277280 (1998).

DOI: 10.1109/ISEIM.1998.741739

[6] Loos A. C., Springer G. S.: Curing of epoxy matrix composites. Journal of Composite Materials, 17, 135169 (1982).

DOI: $\underline{10.1177 / 002199838301700204}$
[7] Lee S-Y., Springer G. S.: Filament winding cylinders I. Process model. Journal of Composite Materials, 24, 1270-1298 (1990). DOI: $10.1177 / 002199839002401202$

[8] Calius E. P., Lee S-Y., Springer G. S.: Filament winding cylinders II. Validation of the process model. Journal of Composite Materials, 24, 1299-1343 (1990). DOI: $10.1177 / 002199839002401203$

[9] Lee S-Y., Springer G. S.: Filament winding cylinders III. Selection of process variables. Journal of Composite Materials, 24, 1344-1366 (1990). DOI: $10.1177 / 002199839002401204$

[10] Bogetti T. A., Gillespie Jr J. W.: Two-dimensional cure simulation of thick thermosetting composites. Journal of Composite Materials, 25, 239-273 (1991).

[11] White S. R., Hahn H. T.: Process modeling of composites materials: Residual stress development during cure. Part I. Model formulation. Journal of Composite Materials, 26, 2402-2422 (1992). DOI: $10.1177 / 002199839202601604$

[12] White S. R., Hahn H. T.: Process modeling of composites materials: Residual stress development during cure. Part II. Experimental validation. Journal of Composite Materials, 26, 2423-2453 (1992). DOI: $10.1177 / 002199839202601605$

[13] Ciriscioli P. R., Wang Q., Springer G. S.: Autoclave curing - Comparisons of model and test results. Journal of Composite Materials, 26, 90-102 (1992). DOI: $10.1177 / 002199839202600106$

[14] Twardowski T. E., Lin S. E., Geil P. H.: Curing in thick composite laminates: Experiment and simulation. Journal of Composite Materials, 27, 216-250 (1993). DOI: $10.1177 / 002199839302700301$

[15] Hojjati M., Hoa S. V. Curing simulation of thick thermosetting composites. Composites Manufacturing, 5, 159-169 (1994). DOI: $10.1016 / 0956-7143(94) 90025-6$

[16] White S. R., Kim Y. K.: Staged curing of composite materials. Composites Part A: Applied Science and Manufacturing, 27, 219-227 (1996). DOI: $\underline{10.1016 / 1359-835 X(95) 00023-U}$

[17] Yi S., Hilton H. H., Ahmad M. F.: A Finite element approach for cure simulation of thermosetting matrix composite. Computers and Structures, 64, 383-388 (1997).

DOI: $\underline{10.1016 / \mathrm{S} 0045-7949(96) 00156-3}$

[18] Kim J. S., Lee D. G.: Development of an autoclave cure cycle with cooling and reheating steps for thick thermoset composite laminates. Journal of Composite Materials, 31, 2264-2282 (1997). DOI: $10.1177 / 002199839703102203$

[19] Blest D. C., Duffy B. R., McKee S., Zulkifle A. K.: Curing simulation of thermoset composites. Composites Part A: Applied Science and manufacturing, 30, 1289-1309 (1999). DOI: $10.1016 / \mathrm{S} 1359-835 \mathrm{X}(99) 00032-9$ 
[20] Park H. C., Lee S. W.: Cure simulation of thick composite structures using the finite element method. Journal of Composite Materials, 35, 188-201 (2001). DOI: $10.1177 / 002199801772662217$

[21] Oh J. H., Lee D. G.: Cure cycle for thick glass/epoxy composite laminates. Journal of Composite Materials, 36, 19-45 (2002). DOI: $\underline{10.1177 / 0021998302036001300}$

[22] Park H. C., Goo N. S., Min K. J., Yoon K. J.: Threedimensional cure simulation of composite structures by the finite element method. Composite Structures, 62, 51-57 (2003).

DOI: $\underline{10.1016 / \mathrm{S} 0263-8223(03) 00083-7}$
[23] Guo Z-S., Du S. Y., Zhang B. M.: Temperature field of thick thermoset composite laminates during cure process. Composites Science and Technology, 65, 517-523 (2005).

DOI: 10.1016/j.compscitech.2004.07.015

[24] Yan X.: Finite element modeling of curing of epoxy matrix composites. Journal of Applied Polymer Science, 103, 2310-2319 (2007).

DOI: $10.1002 /$ app. 24337

[25] Yan X. Q.: Finite element simulation of cure of thick composite: Formulation and validation verification. Journal of Reinforced Plastics and Composites, 27, 339-355 (2008).

DOI: $10.1177 / 0731684407083007$ 